doi:10.12662/2359-618xregea.v10i2.p202-212.2021

\section{DIREITOS DO TITULAR E O ACESSO AO CONHECIMENTO E À INFORMAÇÃO: UM ESTUDO FUNDAMENTADO NOS EMBATES CONTEMPORÂNEOS}

\author{
RIGHTS OF THE HOLDER AND ACCESS TO \\ KNOWLEDGE AND INFORMATION: A STUDY \\ BASED ON CONTEMPORARY CLASHES
}

Vanessa Andriani Maria vanessamariaadvs@gmail.com Mestra em Ciência e Tecnologia Agroindustrial pela Universidade Federal de Pelotas. Membra da Comissão de Direitos Humanos da OAB Subseção Santa Maria - RS desde 2019 e integrante do Grupo de Violência de Gênero da OAB Subseção Santa Maria - RS. Porto Alegre $-R S-B R$.

\section{RESUMO}

A imposição de limites aos direitos do autor exige ponderação entre os interesses de titulares e usuários e deve visar ao bem-estar geral; fundamenta-se em lei e mantém as liberdades fundamentais, tanto a autores, quanto a usuários. A pesquisa caracteriza-se como uma investigação de cunho bibliográfico e exploratório. Tem por objetivo identificar a maneira como o autor pode usar essa proteção, mantendo o equilíbrio entre os seus direitos e os direitos de acesso da sociedade; evitando potenciais conflitos quanto à exploração da obra. Como resultados, observou-se que os recursos computacionais proporcionaram uma significativa mudança no Direito Autoral, inclusive, com a inserção de obras de cunho tecnológico ao rol dos bens protegidos. Sanções administrativas e civis afastariam a necessidade da reprimenda penal, restando à norma penal incriminadora a condição de último instrumento a ser utilizado após a ocorrência do ilícito.

Palavras-chave: Direito Autoral. Informação. Ambiente Digital.

\begin{abstract}
The imposition of limits on copyright requires weighting between the interests of holders and users, and should aim at the general well-being; it is based on law and maintains the fundamental freedoms, both for authors and users. The research is characterized as a bibliographical and exploratory investigation. It aims to identify how the author can use this protection, maintaining the balance between his rights and the access rights of society, avoiding potential conflicts regarding the exploitation of the work. As results, it was observed that computer resources have provided a significant change in Copyright Law, including the insertion of technological works to the list of protected goods. Administrative
\end{abstract}


and civil sanctions would remove the need of criminal reprimand, leaving the incriminating criminal rule the condition of the last instrument to be used after the occurrence of the unlawful.

Keywords: Copyright. Information. Digital Environment.

\section{INTRODUÇÃO}

Os Direitos Autorais compreendem, por sua natureza e finalidade, um conjunto unificado de prerrogativas, cuja intenção fundamental é resguardar o autor e permitir-lhe, de um lado, a defesa da paternidade e da integridade de sua obra e, de outro, a fruição dos proventos econômicos, resultantes de sua utilização, balizados nos mecanismos de tutela dos direitos individuais.

A existência de um conjunto de normas que cuidam de forma específica da questão autoral é basilar para a valorização da pessoa do autor, já que é sua a confissão criativa que proporciona a exteriorização da obra. Ressalta-se que o Direito Autoral protege as obras provenientes do intelecto humano, isto é, resguarda as obras literárias, científicas e artísticas, de tal modo como os programas de computador.

O art. 108, da Lei dos Direitos Autorais, prevê indenização por danos morais em desfavor daquele que utiliza a obra protegida sem mencionar a identificação do autor ou intérprete, bem como a reparação, inclusive, por meio de veiculação em órgãos da imprensa de comunicação, esclarecendo a omissão.

Nas palavras de Bittar (2008):

A tutela geral dos direitos da personalidade compreende modos vários de reação, que permitem ao lesado a obtenção de respostas distintas, em função dos interesses visados, estruturáveis, basicamente, em consonância com os seguintes objetivos: a) cessação de práticas lesivas; b) apreensão de materiais oriundos dessas práticas; c) submissão do agente à cominação de pena; d) reparação de danos materiais e morais; e e) perse- guição criminal do agente (BITTAR, 2008, p. 53).

A proteção ao Direito Autoral está prevista no artigo $5^{\circ}$ da Constituição nos incisos XXVII, XVIII e XIX; entretanto, é importante lembrar que os incisos XXII e XIII, do artigo $5^{\circ}$, tratam, de forma geral, do direito à propriedade, logo, o Direito Autoral também deve respeitar a função social da propriedade, conforme reitera o artigo 170 da Constituição.

Nascimento (2014), tem a seguinte posição a respeito do assunto:

Diante da importância social dos criadores e de suas obras, improvável a afirmativa de que os direitos de autor não são dignos de merecimento da tutela penal. São, assim, merecedores da guarida penal ante a seriedade das lesões aos direitos de autor e as consequências nocivas para o livre desenvolvimento da comunidade (NASCIMENTO, 2014, p. 147).

O trabalho usa como referência a superação do juízo do Direito Autoral como direito absoluto e incontestável, defendendo uma ponderação deste com outros valores e preceitos. É importante observar o interesse do autor ao considerar o Direito Autoral, assim como o interesse público, que representa tanto o interesse de quem usa a concepção, como o de toda a coletividade.

O escopo deste estudo não é criticar os Direitos Autorais, tão necessários para proteger os autores e instigar a criação. Todavia, é de extrema relevância ventilar como essa proteção é conduzida atualmente e de que modo poderia ser feita, não restringindo o acesso ao conhecimento, à cultura e à informação por todos.

Articula-se que este trabalho abrange dois campos de estudo, que são a Ciência da Informação e as Ciências Jurídicas, apresentando caráter transdisciplinar. Tal fato se deve porque versa sobre aspectos relevantes da proteção da informação, relacionados às suas propriedades e ao comportamento, abrangen- 
do, até mesmo, o controle sobre tratamento de dados e sua circulação.

Decorre daí a importância do Direito Autoral que, ao legitimar a conexão existente entre o autor e sua obra, autoriza o desenvolvimento de entidades jurídicas capazes de garantir o reconhecimento de direitos morais e patrimoniais associados à utilização, à reprodução e à disseminação dos bens protegidos.

Neste sentido, o intuito desta pesquisa é identificar a maneira como o autor pode fazer uso desta proteção, de forma a manter o equilíbrio entre os seus direitos e os direitos de acesso da sociedade em geral; evitando potenciais conflitos quanto à exploração da obra. São apresentados parâmetros para a identificação dessa violação caracterizando, assim, o abuso em face do Direito Autoral, e de forma mais específica, as limitações legais do Direito Autoral quanto à reprodução para uso privado de pequenos trechos sem fins lucrativos, à luz da atual legislação pátria.

Pondera-se acerca do panorama do acesso à informação na atualidade. Avaliam-se os aspectos que envolvem a proteção da privacidade, considerando o consentimento como requisito essencial, bem como especificam-se os direitos do titular previstos na Lei de Proteção de Dados. Como percurso metodológico, adota-se a pesquisa bibliográfica e exploratória.

Desse modo, a importância deste trabalho está em fornecer uma contribuição à sociedade, discorrendo sobre um assunto voltado para os direitos autorais, estando no âmbito da proteção legal brasileira e sendo considerado relevante para a efetivação de princípios constitucionais.

\section{DIREITOS AUTORAIS NO BRASIL}

Pode-se expor que a Lei de Acesso à Informação e a Lei Geral de Proteção de Dados nascem com o objetivo de proteger os direitos fundamentais de liberdade e de privacidade com a finalidade de garantir transparência, quanto à circulação de dados e informações, de forma clara, precisa e facilmente acessível.
As primeiras normas voltadas para a proteção do direito autoral no Brasil foram consubstanciadas na Lei $\mathrm{n}^{\mathrm{o}} 496$, de $1^{\circ}$ de agosto de 1898. Seu conteúdo era fundamentalmente o resguardo dado aos autores de obra literária, científica ou artística para fazerem uso de sua criação, assim como serem possuidores de reproduções, tendo a competência de autorizar a publicação, representação, execução ou qualquer outro modo de expressão da obra.

De acordo Rodotà (2008, p. 27), “[...] não é por acaso que seus instrumentos jurídicos de tutela foram predominantemente modelados com base naquele característico do direito burguês por excelência, a propriedade". Segundo o referido autor, a partir de então, embora se mantendo as raízes de seu reconhecimento, a privacidade assume diversos significados, dependendo, desta forma, do objetivo almejado pela coleta de informações.

Bittar salienta que

No Brasil, os Direitos Autorais são regulados, principalmente, pela Lei 9.610 de 1998 , a qual substituiu a lei 5.988, de 1973. Esta legislação objetiva a proteção dos bens intelectuais de caráter literário, científico ou artístico, uma vez que, da análise do conteúdo do Direito de Autor, temos a coexistência de dois direitos autônomos: os de cunho moral, relacionados à proteção da personalidade do criador da obra e outros de cunho patrimonial, relacionados aos direitos de utilização econômica da obra (BITTAR, 2001, p. 50).

Ademais, de acordo com o mesmo autor, temos que

A Carta de 1988 concedeu um privilégio incomum para os direitos de autor ao prevê-los expressamente no rol de direitos e garantias fundamentais. Igual condição se verifica na Constituição dos Estados Unidos da América, na qual os direitos de propriedade intelectual precedem, em tempo e 
dignidade, os princípios que regem os direitos fundamentais. Regra de supremacia federal, os direitos dos autores e titulares sobre suas obras artísticas e literárias são objeto frequente de discussões jurídicas profundas, razão pela qual os constitucionalistas têm dedicado atenção e cuidado na elaboração do equilíbrio das normas e à justeza de sua aplicação (BARBOSA, 2001 apud BITTAR, 2001, p. 10).

Temos, ainda, que a lei vigente não prediz um prazo prescricional particular para o titular do direito autoral agir contra a infração de seus direitos autorais sobre a obra. Dessa forma, na falta de uma previsão expressa, a questão ainda se sujeita à aberta interpretação e discussão.

\section{ASPECTOS RELEVANTES NO ORDENAMENTO JURÍDICO BRASILEIRO SOBRE DIREITO AUTORAL}

Os direitos autorais podem ser tratados como direitos fundamentais da pessoa humana, tendo em vista sua garantia em vários dispositivos de ordem internacional e o amparo expresso da Constituição Federal de 1988, além da legislação infraconstitucional específica da matéria.

Atualmente, diversamente do verificado na legislação autoral brasileira já um tanto quanto antiquada, surgem determinados questionamentos referentes às concepções intelectuais na rede. Entre esses questionamentos, podemos citar o número de acesso às obras na Internet. Como creditá-los ao autor?

A respeito do assunto, Nigri (2006) observa que

Tendo em vista que o direito não pode nem deve permanecer estanque às evoluções tecnológicas, o aparecimento das novas mídias e a consequente integração dos computadores via Internet, bem como a convergên- cia de mídias, constituem, hoje, um grande desafio para os juristas, em especial os autoralistas. Ao mesmo tempo que se alarga o universo de usuários/consumidores dos produtos culturais, agigantam-se os problemas e os questionamentos quanto ao escopo da proteção jurídica e seus meios de controle (NIGRI, 2006, p. 22).

O artigo 215 prevê que compete ao Estado garantir a todos "o pleno exercício dos direitos culturais e acesso às fontes da cultura nacional, e apoiará e incentivará a valorização e a difusão das manifestações culturais" e também o artigo 216 cita que "constitui patrimônio cultural brasileiro os bens de natureza material e imaterial, tomados individualmente ou em conjunto." (BRASIL, 1988, online).

A violação do Direito Autoral é crime tipificado no art. 184 , do CP/1940, e, nessa acepção, é desnecessária a criação de novo tipo incriminador para o caso da conduta criminosa se perfazer via ambiente digital. Ressalta-se que a preservação dos Direitos Autorais requer a correta adaptação da norma à realidade tecnológica.

Os Direitos Autorais encontram amparo constitucional, mediante prerrogativas de ordem moral e patrimonial, as quais permitem a proteção da personalidade do autor em relação à sua obra, assim como o domínio da exploração comercial desta por qualquer meio ou processo conhecido (OLARTE COLLAZOS; ROJAS CHAVARRO, 2010).

Conforme salienta Bittar (2005)

No Direito brasileiro, os Direitos Autorais são tutelados: cumulada, sucessiva ou independentemente em âmbito penal, civil e administrativo. A tripla proteção recebida conforma-se à respectiva natureza de tais direitos e, na prática, à resposta do ordenamento à violação ocorrida está sujeita ao mecanismo acionado pelo lesado que pode, dependendo do caso, desdobrar-se por um, dois ou pelos três ramos citados. Isso porque, haja vis- 
ta a independência das tutelas que prevalece em nosso sistema jurídico, é assegurada ao autor a mais ampla proteção aos seus direitos, proporcionando-lhe a garantia, à defesa e/ou à reparação devida e adequada perante as ameaças ou lesões sofridas (BITTAR, 2005, p. 131-132).

A Lei de Direitos Autorais brasileira - LDA - determina, em seu art. $7^{\circ}$, que "São obras intelectuais protegidas as criações do espírito, expressas por qualquer meio ou fixadas em qualquer suporte, tangível ou intangível [...]" (BRASIL, 1998, online), tomando, por exemplo, os textos de obras literárias, artísticas ou científicas, as obras dramáticas, as obras coreográficas e pantomímicas, as composições musicais tenham ou não letra, as obras audiovisuais, entre outras referidas na legislação.

$\mathrm{O}$ autor será sempre uma pessoa física, enquanto o titular do Direito Autoral poderá ser pessoa física ou jurídica. Segundo os ensinamentos de Abrão (2002)

O sujeito de Direito Autoral, criador de uma obra estética é sempre uma pessoa física, não importando sua condição pessoal, social, política ou jurídica, ou sua crença espiritual. O titular do direito deverá ser uma pessoa física ou jurídica, que adquiriu essa condição por transferência contratual ou decorrência natural (morte do autor). A própria Confederação Internacional das Sociedades de Autores e Compositores - CISAC, composta por 230 organizações de autores para a gestão coletiva, órgão que por sua natureza é direcionado à defesa de interesses corporativistas, já defendeu o entendimento de que o sistema de gestão coletiva deve sujeitar-se às legislações que tratam da concorrência (ABRÃO, 2002, p. 148).

Importante dizer que não é dado ao titular exercer, de maneira absoluta, o direito de exclusivo que lhe é aferido e, em se conquistando poder de mercado, devem ser observadas as regras concorrenciais. A própria Confederação Internacional das Sociedades de Autores e Compositores - CISAC, constituída por 230 organizações de autores para a gestão coletiva, órgão que, por sua classe, é direcionado à defesa de interesses corporativistas, já defendeu o entendimento de que o sistema de gestão coletiva deve sujeitar-se às legislações que abordam da concorrência.

\section{GEST ÃO DE DIREITOS AUTORAIS}

Lipszyc (1999) entende que, hoje, quando se fala em Direitos Autorais, não se deve pensar somente em obras clássicas, como as literárias e as artísticas, porque esse Direito compreende as obras audiovisuais, os programas de computador, as transmissões por cabo e satélite, as redes de informação digital, como a Internet, etc.

São garantidos os direitos morais e patrimoniais aos criadores de obras intelectuais em face da sua criação intelectual, e é o uso da obra pelo público que lhes proporciona a remuneração à qual a proteção lhes dá direito. Para que isso ocorra, é necessária uma eficaz fiscalização para que os direitos de autor não sejam infringidos.

Desse modo, com o desígnio de proteger e efetivar a autorização, o controle, a arrecadação e a distribuição dos direitos, os artistas têm a faculdade de reunirem-se em associações de gestão coletiva dos direitos autorais.

Salienta-se que os mercados mudaram e necessitam de reformulação, pois são mais ágeis. Dessa forma, a revisão da LDA, especialmente no que concerne à gestão coletiva e às limitações da LDA, urge, pois a função social do Direito Autoral é muito importante.

É facultado ao autor ou titular exercer pleno domínio sobre suas obras, em que se pode usar o sistema de gestão coletiva e acordos de representação recíproca entre as entidades das diferentes nações, em uma estrutura capaz de controlar e fiscalizar a utilização das obras em dimensão mundial.

Entretanto, tão logo estabelecidas, tais associações passam a ter funções sindicais, 
uma vez que, na categoria de mandatários dos autores e titulares, têm o direito, e inclusive o dever, de fiscalizar a utilização econômica das obras. São revestidas de poderes delegados pelo artista, em que:

ficam submetidas as condições de atuação das entidades de gestão. É forçado a aderir a uma entidade de gestão, aceitando em bloco as condições desta. $\mathrm{O}$ que quer dizer que o verdadeiro problema para ele passa a ser o da defesa perante a entidade de gestão (ASCENSÃO, 1997, p. 623).

Segundo Maria (2021), os dados confirmam a truculência com que as pessoas estão buscando informações na internet e como os sites jornalísticos de busca e as mídias sociais atuam de forma definitiva na relação entre a produção de informação e o consumo dessa informação.

Importante salientar que os contratos que têm por objeto o direito autoral encontram-se sob a égide dos princípios gerais de contratos e devem cumprimento à função social, boa-fé objetiva e equilíbrio entre as partes. Devem obediência a estes preceitos tanto os contratos realizados entre usuários e associações, quanto entre estas e seus associados.

Com toda essa tecnologia presente e com a facilidade de acesso a qualquer tipo de informação que esteja disponível na Internet, torna-se difícil para o autor de obras protegidas pelo Direito Autoral realizar um controle referente à utilização delas, haja vista que é impossível dimensionar as peregrinações da obra na rede sem mecanismos eficazes de gestão coletiva.

\section{BREVES CONSIDERAÇÕES SOBRE LIMITAÇÕES DO DIREITO AUTORAL}

No Direito Autoral, a função social está atrelada à busca pelo equilíbrio entre a proteção dada ao autor e ao acesso ao conhecimento que a sociedade possui.
Segundo Bittar (1992, p. 26)

[...] os Direitos Autorais - a exemplo de outros direitos privados - vêm sendo constitucionalizados em vários países, compondo o elenco dos denominados 'direitos fundamentais da pessoa' ou 'liberdades públicas', em razão da evolução alcançada no plano da preservação, ante ao Estado, de direitos inatos do homem.

José Afonso da Silva menciona que "A função social da propriedade não se confunde com os sistemas de limitação da propriedade. Estes dizem respeito ao exercício do direito ao proprietário; àquela, à estrutura do direito mesmo, à propriedade" (SILVA, 2005, p. 280).

Os limites do Direito Autoral são como permissões legais para o uso de obras de terceiros, protegidas por Direitos Autorais, independentemente de autorização dos detentores de tais direitos.

O artigo 46 da Lei de Direitos Autorais diz que

Não constitui ofensa aos Direitos $\mathrm{Au}-$ torais:

I - a reprodução:

a) na imprensa diária ou periódica, de notícia ou de artigo informativo, publicado em diários ou periódicos, com a menção do nome do autor, se assinados, e da publicação de onde foram transcritos;

b) em diários ou periódicos, de discursos pronunciados em reuniões públicas de qualquer natureza;

c) de retratos, ou de outra forma de representação da imagem, feitos sob encomenda, quando realizada pelo proprietário do objeto encomendado, não havendo a oposição da pessoa neles representada ou de seus herdeiros; d) de obras literárias, artísticas ou científicas, para uso exclusivo de deficientes visuais, sempre que a reprodução, sem fins comerciais, seja feita mediante o sistema Braille ou outro procedimento em qualquer suporte 
para esses destinatários;

II - a reprodução, em um só exemplar de pequenos trechos, para uso privado do copista, desde que feita por este, sem intuito de lucro;

III - a citação em livros, jornais, revistas ou qualquer outro meio de comunicação, de passagens de qualquer obra, para fins de estudo, crítica ou polêmica, na medida justificada para o fim a atingir, indicando-se o nome do autor e a origem da obra;

IV - o apanhado de lições em estabelecimentos de ensino por aqueles a quem elas se dirigem, vedada sua publicação, integral ou parcial, sem autorização prévia e expressa de quem as ministrou;

V - a utilização de obras literárias, artísticas ou científicas, fonogramas e transmissão de rádio e televisão em estabelecimentos comerciais, exclusivamente para demonstração à clientela, desde que esses estabelecimentos comercializem os suportes ou equipamentos que permitam a sua utilização;

VI - a representação teatral e a execução musical, quando realizadas no recesso familiar ou, para fins exclusivamente didáticos, nos estabelecimentos de ensino, não havendo em qualquer caso intuito de lucro;

VII - a utilização de obras literárias, artísticas ou científicas para produzir prova judiciária ou administrativa;

VIII - a reprodução, em quaisquer obras, de pequenos trechos de obras preexistentes, de qualquer natureza, ou de obra integral, quando de artes plásticas, sempre que a reprodução em si não seja o objetivo principal da obra nova e que não prejudique a exploração normal da obra reproduzida nem cause um prejuízo injustificado aos legítimos interesses dos autores (BRASIL, 1998, online).

Ressalta-se que o direito da exclusividade autoral positivado no art. $5^{\circ}, \mathrm{XXVII}, \mathrm{CRFB}$ não constitui direito absoluto, uma vez que se torna vital a ponderação de valores por meio da leitura da funcionalização. $\mathrm{O}$ art. $5^{\circ}$, XIV e o art. 215, ambos da CRFB, asseguram, indistintamente, o acesso à informação, às fontes da cultura e o exercício dos direitos culturais como direitos subjetivos juridicamente protegidos que transcendem a esfera individual dos sujeitos de direito (SOARES, 2006).

Basso (2008, p. 40) reconhece a existência de uma função social do Direito Autoral que, embora não expresso na $\mathrm{CF} / 1988$, resta implícito do seguinte modo:

Não há nesse inciso uma referência expressa à função que o direito do autor deveria desempenhar na sociedade. Mas, por não se realizar o direito do autor afastado da sociedade e levando-se em conta os demais preceitos expressos e implícitos dessa CF, pode-se afirmar, sem medo de errar, que o direito do autor também deve ser exercido nos limites de sua função social.

Carboni (2008) avalia que essas hipóteses de limitação constituem um rol taxativo:

São hipóteses que não deixam margem para interpretação. Não foram feitas na base de um princípio geral. Não existe, também, na nossa legislação um inciso que permita uma livre reprodução em casos envolvendo educação, pesquisa, ciência e qualquer coisa semelhante, da mesma forma, como não existe um artigo que diga que o impacto econômico da reprodução deva ser levado em consideração (CARBONI, 2008, p. 24).

É importante, também, que se estabeleçam princípios de controle sobre a rede, criando legislações específicas e aplicando-as ao mundo virtual. Sobre o assunto, Chaves (1993, p. 448) esclarece

Dada a rapidez com que se organizam e movimentam os modernos meios de comunicação é-lhes praticamen- 
te impossível pedir, de cada vez, a permissão de quantos tomaram parte, por exemplo, na confecção de um disco: autores da letra e da música, da adaptação, músicos, acompanhantes, eventualmente chefe e componentes de uma orquestra, complicando-se ainda mais a situação quando sejam vários os participantes, como no caso de uma orquestra ou de um coro, e tornando-se verdadeiramente insolúvel o problema quando alguns deles tenham falecido sem que se saiba ao certo se quantos e onde deixaram herdeiros.

Desse modo, o titular de direito autoral tem a seu dispor, na área civil, medidas acautelatórias e até medidas reparatórias, que objetivam proteger o titular do direito de um possível dano eminente, quanto à reparação do dano sofrido, quando da violação de seus direitos.

\section{DIREITO AUTORAL CONTEM- PORÂNEO: PONDERAÇÃO EN- TRE INTERESSES DO AUTOR E DO PÚBLICO?}

Pela facilidade para copiar as obras postas na rede, transmitidas e armazenadas e, pela fragilidade dos sistemas de segurança hoje disponíveis, é de se questionar se, neste novo século, ainda irá se discutir por muito tempo Propriedade Intelectual relativa à Internet. Relacionada à demasiada criminalização dos delitos patrimoniais, Salvador Netto propõe uma evolução das normas na esfera judicial, alinhando os discursos no sentido de aplacar as respostas punitivas e reduzir as hipóteses de tipificação:

As restrições dos conteúdos típicos podem ser feitas tanto em âmbito legislativo, na alteração do texto legal, quanto judicial, por meio de ferramentas de interpretação que restrinjam a criminalização somente àqueles casos de efetivos e significativos prejuízos patrimoniais. Cuida-se, dessa forma, da almejada consagração de um sistema penal mínimo no campo patrimonial, utilizando-se, para tanto, de reformas legislativas, adoção de princípios restritivos de interpretação, sanções penais não pecuniárias, sanções não penais, composições entre vítimas e autores, além de instrumentos processuais (SALVADOR NETTO, 2013, p. 262).

É possível afirmar que a legislação brasileira de Direitos Autorais não promove o uso justo das obras intelectuais, havendo fortes restrições e lacunas que impactam diretamente no acesso ao conhecimento. São diversos os exemplos de situações nas quais o acesso ao conhecimento é negado sob alegação de que se estão protegendo Direitos Autorais, a começar pelos altos preços de livros e pela interpretação restritiva que se tenta impor no Brasil com relação ao artigo 46, VIII, da Lei de Direitos Autorais, vedando-se a fotocópia ao máximo. Os mesmos problemas são encontrados no que diz respeito ao preço para acesso a programas de computadores: dificulta-se a inclusão digital e estimula-se a ilegalidade, não só por causa dos altos custos como também pela, ainda, baixa difusão de programas alternativos gratuitos (GUERRINI, 2008).

A própria ciência da ação de fazer uma cópia perde o sentido quando aborda a reprodução de obras intelectuais na Internet. Tal fato decorre de que, no campo da reprodução, a revolução digital permite a realização de cópias perfeitas a um valor reduzido. Entretanto, no meio digital, geralmente, o acesso não é possível sem a realização de uma cópia.

Salienta Bulos (2008):

A sociedade tem interesse no progresso tecnológico, recompensando o inventor pelo seu trabalho. Em contrapartida, limita essa proteção pelo tempo. Evita-se, assim, que o inventor possa se valer do seu privilégio de exploração econômica para obstar a efetiva utilização de novas tecnologias, tolhendo a existência de novas 
descobertas benéficas à sociedade e ao desenvolvimento econômico do País.Diante da análise feita até aqui, acredita-se que o impacto do Direito Autoral sobre práticas diárias é essencial para as práticas educacionais que determinados usos permitidos estejam expressos na lei, para afastar dúvidas no campo da educação (BULOS, 2008, p. 210-211).

Futuramente, necessitar-se-á de maior celeridade, porquanto devido ao incremento tecnológico alcançado pela sociedade, em especial com relação à Internet e à facilidade da editoração digital, ou os autores verão seus direitos morais e patrimoniais esvaecerem diante da falta de legislação específica que regule não só esses direitos, mas todas as atividades decorrentes desse novo meio.

\section{CONCLUSÃO}

Conclui-se que a legislação autoral em vigor no Brasil tem a função de proteger os direitos de autor, uma vez que o fato de se encontrarem obras disponíveis para pesquisa pública em meio eletrônico não sugere que estas são públicas ou de domínio público, porquanto são de titularidade do autor ou de terceiro legitimado.

Com o intuito de não desmerecer o autor, fazer uso de suas palavras é permitido, desde que as fontes sejam devidamente referenciadas. Logo, a citação de trechos e passagens de obras de vários autores com a finalidade de fundamentar a arguição do trabalho, compará-lo, não constitui violação de Direitos Autorais, desde que haja a devida referência dos autores e suas obras empregadas.

O estudo considerou basilar a existência de uma legislação que abordasse especificamente o assunto dos Direitos Autorais no País. Tal afirmativa se fundamenta no reconhecimento do papel dos autores e de suas obras para o desenvolvimento da humanidade, bem como na formação científica dos povos. Ademais, também se ponderou indissociável o vínculo entre o autor e a sua obra, visto que a criação intelectual resulta do esforço pessoal de seu autor e, por conseguinte, sua utilização deve gerar a devida recompensa em favor de seu titular, tanto na forma de reconhecimento, quanto de benefícios patrimoniais.

A disponibilização de conteúdos na Internet abrange sempre aspectos pautados às questões de direitos autorais. Em muitos aspectos, a lei ainda não acompanha a evolução das tecnologias digitais, haja vista as inúmeras possibilidades de criação do intelecto humano. Nessa acepção, há necessidade tanto de adequação das normas como de sua aplicabilidade em casos concretos. A falta de uma padronização das cessões de direitos em periódicos científicos eletrônicos retrata bem esse quadro.

Existe a necessidade de se discutir a atualização dos preceitos legais para que haja efetiva proteção aos direitos econômicos dos autores e editores.

Diversas informações encontram-se dispostas nos mais variados meios de comunicação, principalmente no meio eletrônico. É de extrema relevância saber utilizá-las de forma apropriada, na execução de um trabalho de qualidade.

Ademais, aos profissionais do Direito, principalmente, incumbe acompanhar a evolução decorrente da Internet e as relações por meio do ciberespaço, pois, no mundo das redes de computadores, para pessoas, inteligências e serviços, praticamente não existem fronteiras para o acesso às informações, e essas não são regulamentadas por um órgão único, mas por normas comuns e acordos de cooperação mútua entre usuários.

Portanto, poderemos aprofundar-nos em artigos futuros, mas a finalidade, neste momento, é conscientizar os usuários de tecnologia que, para caracterização da infração de direitos de autor, basta seu uso sem consentimento, não sendo a mera publicação em mídias digitais, uma autorização tácita. Para uso, edição etc. Será necessário entrar em contato e pedir autorização. 


\section{REFERÊNCIAS}

ABRÃO, Eliane Yachouh. Direitos de Autor e Direitos Conexos. São Paulo: Editora do Brasil, 2002.

ASCENSÃO, José de Oliveira. Direito Autoral. Rio de Janeiro: Renovar, 1997.

BASSO, Maristela. A tutela constitucional da propriedade intelectual na carta de 1988 : avanço indiscutível. Revista de informação legislativa, v. 45, n. 179, p. 39-41, jul./set. 2008.

BITTAR, Carlos Alberto. Direito de autor. 2. ed. Rio de Janeiro: Forense Universitária, 1994.

BITTAR, Carlos Alberto. Direito de Autor. 4. ed. Rio de Janeiro: Forense Universitária, 2005.

BITTAR, Carlos Alberto. Os direitos da personalidade. 5. ed. Rio de Janeiro: Forense Universitária, 2001.

BRASIL. Constituição da república federativa do brasil de 1988. Brasília, DF: Presidência da República, 1988. Disponível em: http:// www.planalto.gov.br/ccivil_03/constituicao/ constituicao.htm. Acesso em: 16 de fevereiro de 2021.

BRASIL. Lei $n^{0}$ 9.610, de 19 de fevereiro de 1998. Altera, atualiza e consolida a legislação sobre direitos autorais e dá outras providências. Brasília, DF: Presidência da República, 1998. Disponível em: http://www.planalto.gov.br/ccivil_03/leis/19610.htm. Acesso em: 16 de fevereiro de 2021.

BULOS, Uadi Lammêgo. Constituição Federal Anotada. 8. ed. São Paulo: Saraiva, 2008.

CARBONI, Guilherme. Aspectos Gerais da Teoria da Função Social do Direito de Autor. Disponível em: https://gcarbonicombr.files. wordpress.com/2016/08/aspectos-gerais-da-teoria-da-func3a7c3a3o-social-do-direito-de-autor.pdf: Acesso em: 26 maio 2020.
CARBONI, Guilherme. Limitações e exceções da lei. In: FÓRUM Nacional de Direito Autoral. Seminário Direitos Autorais e Acesso à Cultura (2008: São Paulo, SP). Anais do Seminário Direitos Autorais e Acesso à Cultura [recurso eletrônico], 27 e 28 de agosto de 2008. Brasília: Ministério da Cultura, Coordenação Geral de Direito Autoral, 2008. p. 24-25.

CHAVES, Antonio. Direitos autorais na radiodifusão (Rádio e TV). Revista Forense, v. 284, out./dez. 1993.

GUERRINI, Estela Waksberg. Direitos Autorais e os Direitos dos Consumidores. In: FÓRUM Nacional de Direito Autoral. Seminário Direitos Autorais e Acesso à Cultura (2008: São Paulo, SP). Anais do Seminário Direitos Autorais e Acesso à Cultura [recurso eletrônico], 27 e 28 de agosto de 2008. Brasília: Ministério da Cultura, Coordenação Geral de Direito Autoral, 2008.

LIPSZYC, Délia. Convenções internacionais em matéria de direito de autor. In: LAHORGUE, Maria Alice; COSTA, Carlos Fernando (org.). Anais dos seminários OMPI de propriedade intelectual e mecanismos de transferência de tecnologia. Porto Alegre: Editora UFRGS, 1999.

MARIA, Vanessa. O Trânsito de Dados nas Redes Sociais e a Concepção da Informação sob a Esfera das Fake News. Ago, 2020. Disponível em: https://ambitojuridico.com.br/cadernos/ outros/o-transito-de-dados-nas-redes-sociais-e-a-concepcao-da-informacao-sob-a-esfera-das-fake-news/: Acesso em: 18 jul. 2021.

NASCIMENTO, Elisa Gattás Fernandes do. A tutela penal dos Direitos Autorais. 2014. 147 f. Dissertação (Mestrado) - Universidade de São Paulo, Faculdade de Direito, Programa de Pós Graduação em Direito, São Paulo, 2014.

NIGRI, Deborah Fisch. Direito Autoral e a Convergência de Mídias: cadernos de direito da internet. Rio de Janeiro: Editora Lumen Juris, 2006. v. 2. 
OLARTE COLLAZOS, JORGE Mario; ROJAS CHAVARRO; Miguel Angelo. La protección del derecho de autor y los derechos conexos en el ámbito penal. Dirección Nacional de Derecho de Autor, Ministerio del Interior y de Justicia. Colômbia, 2010. Disponível em: http://www.derechodeautor.gov. co/documents/10181/11769/La+proteccin+del+derecho + de+autor $+y+$ los + derechos + cone$\mathrm{xos}+\mathrm{en}+\mathrm{el}+$ ambito + penal + sep $+15+\mathrm{de}+2010$. pdf/75686fc1-c9be-4dc3-b1d5-efcd5f4be949: Acesso em: 26 maio. 2020.

RODOTÁ, Stefano. A vida na sociedade da vigilância: a privacidade hoje. Rio de Janeiro: Renovar, 2008.

SALVADOR NETTO, Alamiro Velludo. Direito penal e propriedade privada: a racionalidade do sistema penal na tutela do patrimônio. 2013. 352 f. Tese (Livre-docência) - Faculdade de Direito, Universidade de São Paulo, São Paulo, 2013.

SILVA, José Afonso da. Curso de Direito Constitucional Positivo. São Paulo: Malheiros, 2005.

SOARES, Sávio de Aguiar. Direitos autorais morais e sua tutela no estado democrático de direito brasileiro. Revista da Ordem dos Advogados do Brasil, Brasília, v. 36, n. 82, p. 8499, jan./jun. 2006. 